\title{
A case of an abdominal wall cystic urachal carcinoma in an unusual location
}

\author{
Kyoungyul Kim ${ }^{1}$, Minsun Jung ${ }^{2}$, Dongyoung Lim³ , Young-Joon Ryu*1,3 \\ ${ }^{1}$ Department of Pathology, Kangwon National University Hospital, Chuncheon, Korea \\ ${ }^{2}$ Department of Pathology, Seoul National University College of Medicine, Seoul, Korea \\ ${ }^{3}$ Department of Pathology, Kangwon Nation University College of Medicine, Chuncheon, Korea
}

Received: April 11, 2017

DOI: $10.5430 /$ crcp.v4n3p16
Accepted: August 8, $2017 \quad$ Online Published: August 20, 2017

URL: https://doi.org/10.5430/crcp.v4n3p16

\begin{abstract}
A solitary cystic lesion in the abdominal wall is generally benign, such as an omental cyst, mesenteric cyst, enteric duplication cyst, cystic mesothelioma, or skin appendage tumor. Furthermore, most malignancies in the urachal remnant are intraperitoneal lesions, and generally develop on the anterior aspect of the bladder dome. Moreover, most urachal glandular malignant neoplasms are the mucinous cystic type. We report a cystic urachal adenocarcinoma that presented as an abdominal wall cystic lesion. A 42-year-old woman was admitted to Kangwon National University Hospital for a 5-cm palpable abdominal wall mass. Conservative surgical excision was performed with subsequent histological and immunohistochemical evaluations, but only a few non-mucinous invasive glands and finger-like growths were noted. During a 2-year period, the tumor recurred several times along the urachal tract and metastasized to the regional lymph nodes. Despite receiving chemotherapy, the patient died 2 years after the first surgery.
\end{abstract}

Key Words: Adenocarcinoma, Abdominal wall, Urachal cyst

\section{INTRODUCTION}

The urachus is a vestigial tubular structure that connects the urinary bladder to the allantois during early development. The urachal remnant can be incidentally detected during $32 \%$ of adult bladder autopsies. The urachal remnant typically arises from the bladder apex and then continues upward within the space of Retzius through a varied course toward the umbilicus. ${ }^{[1]}$ Carcinoma can also arise from any of the urachal remnant compartments, with most carcinomas originating from the canal epithelium in adults. ${ }^{[2-4]}$ Glandular neoplasms in the urachus are classified as benign mucinous cystic tumors, borderline malignant mucinous cystic tumors, and malignant non-cystic neoplasms. Previous reports have indicated that most cystic forms of urachal adenocarcinoma are the mucinous type. ${ }^{[5]}$ Immunohistochemical staining of urachal adenocarcinoma typically reveals strong and uniform positivity for cytokeratin 7 (CK7), variable expression of CK20 and CDX-2, and no nuclear expression of ß-catenin. ${ }^{[6]}$ All reported cases of this adenocarcinoma have been located in the intraperitoneal area, and generally developed on the anterior aspect of the bladder dome. ${ }^{[1-16]}$ We report the first case of a cystic non-mucinous urachal adenocarcinoma with finger-like growth in the abdominal wall.

\section{CASE REPORT}

A 42-year-old woman was admitted to Kangwon National University Hospital for a palpable abdominal wall mass. Abdominal computed tomography revealed a $17-\mathrm{cm}$ well-

\footnotetext{
*Correspondence: Young-Joon Ryu, Prof.; Email: mindmader@gmail.com; Address: Department of Pathology, Kangwon National University College of Medicine, Hyo-Ja-2 Dong, Chuncheon, 200-701, Korea.
} 
defined multi-septated cystic mass in the midline anterior abdominal wall (see Figure 1A). Conservative surgical excision was performed based on the impression that the mass was benign, and gross examination revealed that the mass was $17 \mathrm{~cm} \times 5 \mathrm{~cm} \times 4 \mathrm{~cm}$, well circumscribed, round, cystic, and surrounded by abdominal skeletal muscle. Multiple cysts contained clear serous fluid (see Figure 1B). Microscopic examination revealed benign cysts of various sizes, and the cyst walls were lined with simple or stratified cuboidal epithelium and fibrous tissue (see Figure 1C). Invasive glands (see Figure 1D) and finger-like projections were noted in the intraluminal epithelium of some cysts (see Figure 1E). The mass also exhibited a moderately differentiated glandular structure, and the cells exhibited nuclear hyperchromasia, irregular nuclei, and a high N/C ratio (see Figure 1F). The lymph node metastasis exhibited a papillary growth pattern (see Figure 1G). The entire excised specimen was subjected to immunohistochemical staining, which revealed strong and uniform positivity for pan CK and CK7 (see Figure 1H) and membrane expression for $B$-catenin, but no expression of CDX-2, CK20, CD31, CD34, factor VIII, SMA, HMB45, and myoD1. The resection margin was indeterminate. During a 2-year period, the adenocarcinoma recurred several times along the urachal tract and metastasized to the regional lymph nodes. Despite receiving chemotherapy, the patient died 2 years after the first surgery.
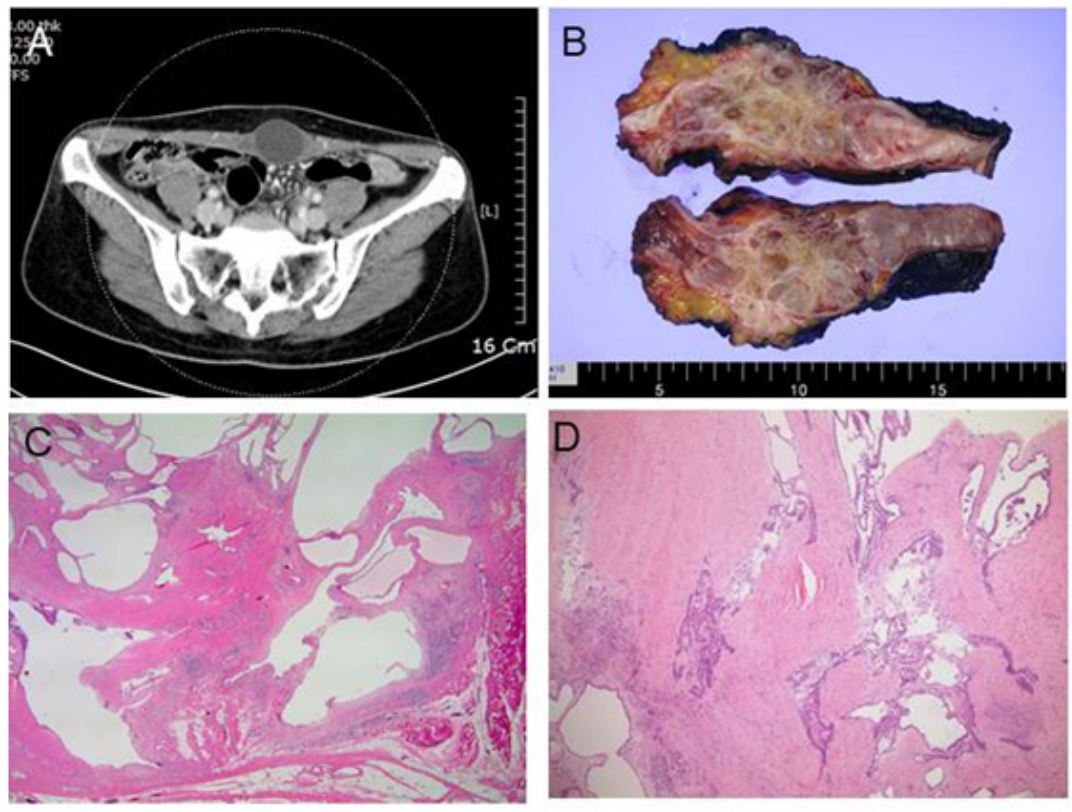
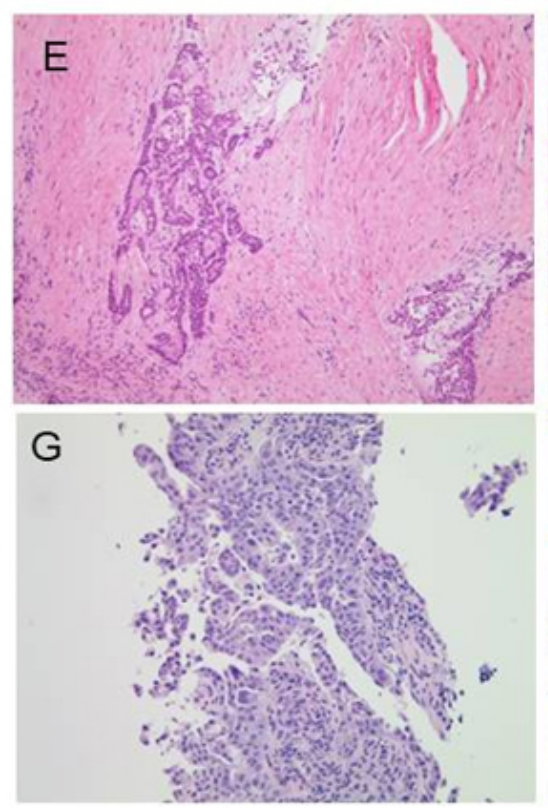
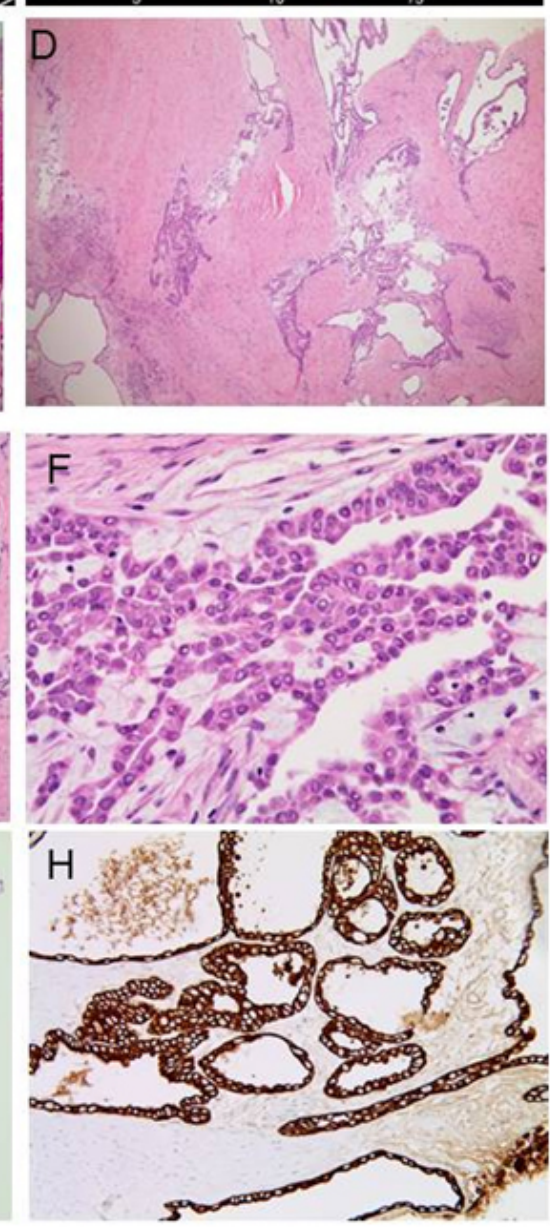

Figure 1. Radiological and pathological findings from the abdominal wall mass (A) Abdominal Computed Tomography (CT) revealed an anterior abdominal cystic mass. (B) The cut surface of the excised specimen exhibited multi-septated spaces that were filled with a clear fluid $(5 \mathrm{~cm} \times 4 \mathrm{~cm} \times$ $17 \mathrm{~cm}$ ). (C) Low-power imaging of the tumor revealed cysts of various sizes, as well as cystic wall-lining cells that are non-mucinous simple or stratified epithelium (hematoxylin and eosin, $\times 12.5$ ). (D) Some malignant components are observed on a benign background $(\times 40)$, and $(E)$ moderately differentiated glandular features are visible $(\times 100)$. $(F)$ The tumor cells have nuclear irregularity and a high N/C ratio. $(G-H)$ All glands of the tumor were positive for pan cytokeratin and cytokeratin 7 . 


\section{Discussion}

The preoperative differential diagnoses of an abdominal wall cystic lesion include an omental cyst, mesenteric cyst, urachal cyst, cystic mesothelioma of the peritoneum, enteric duplicated cyst, cystic teratoma, pseudocyst, skin appendage tumor, and extrahepatic echinococcosis. Most of these lesions are benign, and an urachal carcinoma in an abdominal wall cyst is rare.

Previous reports have indicated that the predominant histological type of urachal carcinoma is mucinous cystic adenocarcinoma, followed by non-cystic invasive adenocarcinoma. ${ }^{[5,7]}$ However, the present case involved a cystic and non-mucinous adenocarcinoma, where the tumor cells had raised the cyst-lining epithelium and developed into fingerlike intraluminal projections in some areas. Therefore, this case was diagnosed as urachal adenocarcinoma, not otherwise specified (NOS).

In addition, this case involved an unusual location, as urachal adenocarcinoma typically involves the antero-inferior aspect of the bladder wall or along the bladder wall, especially at the dome. ${ }^{[4]}$ Furthermore, the average patient at the diagnosis of urachal adenocarcinoma is 57.2 years, ${ }^{[8]}$ while our patient was relatively young (42 years). Moreover, the prognosis of patients with urachal carcinoma is generally poor because their tumors often are not diagnosed until the late stages. ${ }^{[7]}$ This patient might have been expected to experience a relatively good outcome, based on several factors: a relatively small carcinoma area $(<1 \mathrm{~cm})$, and a abdominal wall location in the mass.

This case highlights the potential limitations of a preoperative radiological diagnosis of an abdominal wall cystic adenocarcinoma, as well as the importance of a careful operative margin resection despite any impression that the mass is benign.

\section{FUNDING}

This report was supported by a Research Grant from Kangwon National University (C1010345-01-01).

\section{CONFLiCTS OF InTEREST Disclosure}

The authors declare that they have no potential conflicts of interest with respect to the research, authorship, and/or publications of this article.

\section{REFERENCES}

[1] Schubert GE, Pavkovic MB, Bethke-Bedürftig BA. Tubular urachal remnants in adult bladders. J Urol. 1982; 127: 40-42. https: //doi.org/10.1016/S0022-5347(17)53595-8

[2] Paner GP, Barkan GA, Mehta V, et al. Urachal carcinomas of the nonglandular type: salient features and considerations in pathologic diagnosis. Am J Surg Pathol. 2012; 36: 432-442. PMid: 22301493. https://doi.org/10.1097/PAS.0b013e31823fe49c

[3] Siefker-Radtke A. Urachal carcinoma: surgical and chemotherapeutic options. Expert Rev Anticancer Ther. 2006; 6: 1715-1721. PMid: 17181485. https://doi.org/10.1586/14737140.6.12.1715

[4] Gopalan A, Sharp DS, Fine SW, et al. Urachal carcinoma: a clinicopathologic analysis of 24 cases with outcome correlation. Am J Surg Pathol. 2009; 33: 659-668. PMid: 19252435. https: //doi.org/10.1097/PAS.0b013e31819aa4ae

[5] Amin MB, Smith SC, Eble JN, et al. Glandular neoplasms of the urachus: a report of 55 cases emphasizing mucinous cystic tumors with proposed classification. Am J Surg Pathol. 2014; 38: 1033-1045. https://doi.org/10.1097/PAS.0000000000000250

[6] Paner GP, McKenney JK, Barkan GA, et al. Immunohistochemical analysis in a morphologic spectrum of urachal epithelial neoplasms: diagnostic implications and pitfalls. Am J Surg Pathol. 2011; 35: 787-798. PMid: 21572312. https://doi.org/10.1097/PAS.0b 013e3182189c11

[7] Ashley RA, Inman BA, Sebo TJ, et al. Urachal carcinoma: clinicopathologic features and long-term outcomes of an aggressive malignancy. Cancer. 2006; 107: 712-720. PMid: 16826585. https: //doi.org/10.1002/cncr. 22060

[8] Henly DR, Farrow GM, Zincke H. Urachal cancer: role of conservative surgery. Urology. 1993; 42: 635-639. https ://doi .org/10.1 016/0090-4295 (93) 90526-G
[9] Yasui T, Okamura T, Akita $\mathrm{H}$, et al. Urethral recurrence of an urachal carcinoma: a case report. Int J Urol. 1997; 4: 106-108. PMid: 9179681. https://doi.org/10.1111/j.1442-2042.19 97.tb00154.x

[10] Paul AB, Hunt CR, Harney JM, et al. Stage 0 mucinous adenocarcinoma in situ of the urachus. J Clin Pathol. 1998; 51: 483-484. PMid: 9771454. https://doi.org/10.1136/jcp.51.6.483

[11] Kato H, Hayama M, Kobayashi M, et al. Large intestinal typeurachal adenocarcinoma with focal expression of prostatic specific antigen. Int J Urol. 2004; 11: 1033-1035. PMid: 15509213. https://doi.org/10.1111/j.1442-2042.2004.00940.x

[12] Pal DK, Chowdhury MK. Urachal adenocarcinoma masquerading as an urachal cyst. Indian J Surg. 2008; 70: 135-137. PMid: 23133041 https://doi.org/10.1007/s12262-008-0037-5

[13] Scabini S, Rimini E, Romairone E, et al. Urachal tumour: case report of a poorly understood carcinoma. World J Surg Oncol. 2009; 7: 82. PMid: 19895702. https://doi.org/10.1186/1477-7819-7-8 2

[14] Lamb BW, Vaidyanathan R, Laniado M, et al. Mucinous adenocarcinoma of the urachal remnant with pseudomyxoma peritonei. Urol $\mathrm{J}$. 2010; 7: 138-139. PMid: 20535705.

[15] Fanning DM, Sabah M, Conlon PJ, et al. An unusual case of cancer of the urachal remnant following repair of bladder exstrophy. Ir J Med Sci. 2011; 180: 913-915. PMid: 19294480. https: //doi.org/10.1007/s11845-009-0310-z

[16] Bissonnette ML, Kocherginsky M, Tretiakova M, et al. The different morphologies of urachal adenocarcinoma do not discriminate genomically by micro-RNA expression profiling. Hum Pathol. 2013; 44: 1605-1611. PMid: 23528864. https ://doi.org/10.1016/j.hu mpath.2013.01.008 